\title{
MODELLING OF NO ADSORPTION IN FIXED BED ON ACTIVATED CARBON
}

\author{
Lenka Kuboňová $^{1}$, Lucie Obalová ${ }^{* 1}$, Oldřich Vlach ${ }^{2}$, Ivana Troppová ${ }^{1}$, \\ Jaroslav Kalousek ${ }^{1}$
}

${ }^{1}$ VŠB-Technical University of Ostrava, Centre for Environmental Technology, 17. listopadu 15/2172, 708 33, Ostrava, Czech Republic

${ }^{2}$ VŠB-Technical University of Ostrava, Department of Applied Mathematics, 17. listopadu 15/2172, 708 33, Ostrava, Czech Republic

\begin{abstract}
Adsorption experiments of nitric oxide in nitrogen carrier gas were held on activated carbon in a fixed bed flow system. Breakthrough curves describing the dependence of exit concentrations of nitric oxide on time were matched with theoretical response curves calculated from the linear driving force model (LDF). The model assumes Langmuir adsorption isotherm for the description of non-linear equilibrium and overall mass transfer coefficient for mass transfer mechanism. Overall mass transfer coefficients were obtained by the method of least squares for fitting numerically modelled breakthrough curves with experimental breakthrough curves. It was found that LDF model fits all the breakthrough curves and it is a useful tool for modelling purposes.
\end{abstract}

Keywords: adsorption, activated carbon, nitric oxide, linear driving force model, mass transfer coefficient

\section{INTRODUCTION}

Nitric oxide is an environmental pollutant in a group of nitrogen oxides $\left(\mathrm{NO}_{\mathrm{x}}\right)$ mainly produced by combustion processes in automobile engines and fossil fuel power plants. Nitric oxide is rapidly oxidised in air to nitrogen dioxide $\left(\mathrm{NO}_{2}\right)$ and to nitric acid content in acid rain. Both $\mathrm{NO}$ and $\mathrm{NO}_{2}$ participate in ozone layer depletion. Therefore, minimisation of $\mathrm{NO}_{x}$ emission is an important issue. These emissions can be diminished either by limiting their formation at the origin or by the adsorption/chemical transformation of pollutants using various heterogeneous systems. The choice of an appropriate method depends on the concrete source of $\mathrm{NO}_{x}$ emissions and on investment and operational expenses. Adsorption is mainly used for filtration of air flowing to sensitive electronic facilities, in museums, galleries or in gas masks (Herčík, 2004).

The approach of adsorption of nitric oxide (NO) on activated carbon and other sorbents has been widely characterised (Goméz, 2005; Zhang, 2008; Zhu 2005). The process of adsorption can be described by breakthrough curves as the response to step concentration inputs. Mathematical description of breakthrough curves for dynamic adsorption is important for filtration facilities design and can be used for describing adsorption kinetics on heterogeneous solids, for evaluating adsorption column dynamics and adsorptive process design (Sircar, 2000). Numerous models describing fixed bed adsorption have been published (Babu, 2005; Gupta, 2002; Hang, 2003; Ruthven, 1984; Šrámek 2005),

*Corresponding author, e-mail: lucie.obalova@vsb.cz 
using simplified linear driving force model (LDF) as well (Amanullah, 1999a, 2000b; Dantas, 2011; Murillo, 2004; Tantet, 1995).

The aim of the present paper is the description of equilibrium and dynamics of NO adsorption on commercial activated carbon using the breakthrough curve method. Experimental breakthrough curves are used to obtain equilibrium data, Langmuir and Freundlich equilibrium adsorption models were applied for their description. The overall mass transfer coefficients are determined from mathematical description of breakthrough curves and their dependency on experimental conditions. Known overall mass transfer coefficients are used for the estimation of NO surface diffusivity over interior surface of activated carbon.

\section{THEORETICAL}

The choice of the mathematical model of breakthrough curves depends on type of adsorbate and internal structure of adsorbent (Gupta, 2004). In the present work the simplified linear driving force model (LDF) was used. The LDF mathematical model is based on the following assumptions:

- Isothermal conditions within the adsorption column are expected.

- The adsorbate (NO) is at trace levels in non-adsorbing inert gas $\left(\mathrm{N}_{2}\right)$.

- Pressure-drop along the adsorbent bed is negligible (isobaric condition).

- Intra-particle pore diffusivity and external-film mass transfer coefficient are constant along the adsorbent bed.

\subsection{Adsorption isotherms}

Adsorption capacities $q^{*}$ for different initial NO concentrations were evaluated by dynamic method of breakthrough curve measurements. Adsorption capacity $q^{*}$, meaning the equilibrium concentration of NO in the solid phase, was calculated by Eq. (2) where time equivalent $t_{t}$ was calculated by numerical integration using trapezoidal method (Eq. 1), (Sumathi, 2010).

$$
\begin{gathered}
t_{t}=\int_{0}^{\infty}\left(1-\frac{c}{c_{0}}\right) d t \\
q^{*}=\frac{Q_{v} \cdot t_{t} \cdot y \cdot \rho_{N O} \cdot \rho_{p}}{m}
\end{gathered}
$$

LDF model assumes Langmuir adsorption isotherm to describe non-linear equilibrium (Eq. 3). Adsorption is considered to be isothermal hence adsorption heat is neglected.

$$
\frac{q^{*}}{q_{s}}=\frac{b \cdot c}{1+b \cdot c}
$$

Parameters of isotherm $q_{s}$ and $b$ were evaluated by linear regression using a linearised form of Langmuir isotherm, Eq. (4).

$$
\frac{c}{q^{*}}=\frac{1}{q_{s}} \cdot c+\frac{1}{q_{s} b}
$$

For comparison of better fitted data, Freundlich isotherm was applied as well (Eq. 5) with the linearised form (Eqn 6) to obtain parameters of isotherm $K_{F}$ and $1 / n$.

$$
q^{*}=K_{F} c^{1 / n}
$$




$$
\ln q^{*}=1 / n \cdot \ln c+\ln K_{F}
$$

\subsection{Overall mass balance in adsorption column}

Axial dispersed plug flow used in LDF model is described by mass balance for the gas phase (Eq. 7). A deviation from ideal plug flow caused by axial mixing is proposed. Accumulation, convection, axial dispersion and interfacial flux terms are included in this equation (Šrámek, 2005).

$$
\frac{\delta c}{\delta t}=D_{L} \cdot \frac{\delta^{2} c}{\delta z^{2}}-\left(v \cdot \frac{\delta c}{\delta z}+c \cdot \frac{\delta v}{\delta z}\right)-\frac{1-\varepsilon}{\varepsilon} \cdot \frac{\delta \bar{q}}{\delta t}
$$

In a system where adsorbate is present at low concentrations in an inert carrier gas, the fluid volume flow across adsorbent bed is constant thus the term $c \cdot \frac{\delta v}{\delta z}$ is negligible (Gupta, 2004; Ruthven, 1984).

\subsection{Mass transfer resistance between fluid and solid phase}

According to LDF model, the rate of adsorption of a single adsorbate into adsorbent particles is characterised by overall effective mass transfer coefficient $k$ (Murillo, 2004; Ruthven, 1984). Equilibrium is assumed between the surface and the fluid at each point inside the adsorbent particle (Mutlu, 1998). The value of $k$ is according to literature (Amanullah, 2000; Murillo, 2004) estimated to be in the range of $10^{-3}-10^{-4} \mathrm{~s}^{-1}$. Mass balance for the solid phase is described by Eq. (8).

$$
\frac{d \bar{q}}{d t}=k \cdot\left(q^{*}-\bar{q}\right)
$$

\subsection{Initial and boundary conditions}

As Eq. (7) is nonlinear, partial differential equation with non-linear term described by Eq. (8), initial condition (Eq. 9) and boundary conditions (Eqs. 10, 11) must be determined.

$$
\begin{gathered}
c(z, 0)=0 \\
\left.D_{L} \cdot \frac{\partial c}{\partial z}\right|_{z=0}=-v \cdot\left(c_{0}-\left.c\right|_{0}\right) \\
\left.\frac{\partial c}{\partial z}\right|_{z=L}=0
\end{gathered}
$$

Mass transfer coefficients were optimised by fitting the experimental data with the mathematical model Eqs. (7-11), (Amanullah, 2000; Murillo, 2004; Tantet, 1995). The numerical method applied to solve the equations was the least squares technique in the MATLAB built-in solver.

\section{EXPERIMENTAL}

Adsorption experiments of $\mathrm{NO}$ on activated carbon were held on an apparatus composed of sampling and mixing of gases (inert gas Ar, adsorptive gas $\mathrm{NO}$ and carrier gas $\mathrm{N}_{2}$ ), an adsorber column and an analytical section. The adsorber column was made of acrylic glass, in length of $18 \mathrm{~cm}$ and an inner 
diameter of $3.4 \mathrm{~cm}$ and filled with activated carbon $\left(m=76 \mathrm{~g}\right.$, particle diameter $d_{p}$ in range of $2-2.8$ $\mathrm{mm}$; particle density of $0.73 \mathrm{~g} / \mathrm{cm}^{3}$, mean micropore radius of $0.91 \mathrm{~nm}$, MA C6 D40 CZ, Resorbent). The initial NO concentrations were in the range of $0.28-1.0 \mathrm{~mol} \%$ in a total volume flow of 350 $\mathrm{ml} / \mathrm{min}$. Outlet concentrations were analysed by a quadrupole mass spectrometer RGA 200 (Prevac). The operating variables (room temperature, atmospheric pressure) were kept identical at the same adsorbent amount in the gas mixture $\mathrm{NO} / \mathrm{Ar} / \mathrm{N}_{2}$, while the saturated adsorbent was desorbed in $\mathrm{N}_{2}$ flow.

\section{RESULTS AND DISCUSSION}

\subsection{Experimental breakthrough curves}

Experimental breakthrough curves of NO adsorption on activated carbon are depicted in Figure 1. In the agreement with literature (Babu, 2005; Gupta, 2002), steeper breakthrough curves are found and breakthrough time of activated carbon saturation decreases with increasing concentrations. Hence equilibrium was reached faster with higher inlet NO concentrations.

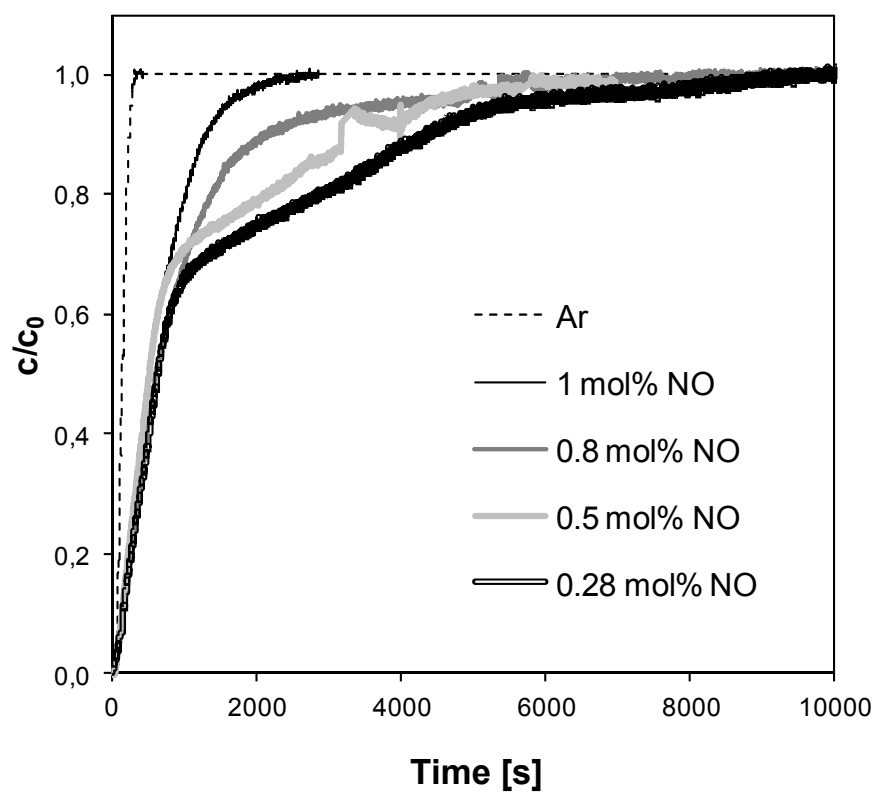

Fig. 1. Experimental breakthrough curves of NO adsorption on activated carbon

\subsection{Evaluation of adsorption isotherm}

Adsorption capacities of activated carbon were calculated from the experimental breakthrough curves (Eqn 2) and results are summarised in Table 1. Adsorption capacity decreased with decreasing NO concentration. The same trend was reported by (Sumathi, 2010). Langmuir and Freundlich isotherms were applied to fit equilibrium values. It was found that Langmuir isotherm fitted better than Freundlich one, see Fig. 2, 3. The constants $q_{s}, b$ were evaluated from the linearised form of Langmuir isotherm $\left(q_{s}=4.14 .10^{-4} \mathrm{~g} \cdot \mathrm{cm}^{-3}, b=588853.7 \mathrm{~cm}^{3} \cdot \mathrm{g}^{-1}\right)$ used in LDF model. 
Table 1. Adsorption capacities of activated carbon for different NO concentrations

\begin{tabular}{|c|c|c|c|}
\hline \multicolumn{2}{|c|}{ NO concentration } & \multicolumn{2}{c|}{ Adsorption capacity } \\
\hline$[\mathrm{mol} \%]$ & {$[\mathrm{mg} / \mathrm{l}]$} & {$[\mathrm{ml} \mathrm{NO} / \mathrm{g}$ a.u.] } & {$\left[\mathrm{g} \mathrm{NO}^{1)} / \mathrm{g}\right.$ a.u.] } \\
\hline 1.00 & 12.48 & 0.39 & $4.89 .10^{-4}$ \\
\hline 0.80 & 9.98 & 0.40 & $4.98 .10^{-4}$ \\
\hline 0.50 & 6.24 & 0.37 & $4.64 .10^{-4}$ \\
\hline 0.28 & 3.49 & 0.29 & $3.62 .10^{-4}$ \\
\hline
\end{tabular}

${ }^{1)} \rho_{\mathrm{NO}}=1 \cdot 25 \cdot 10^{-3} \mathrm{~g} \cdot \mathrm{cm}^{-3}\left(20^{\circ} \mathrm{C}, 101 \mathrm{kPa}\right)$

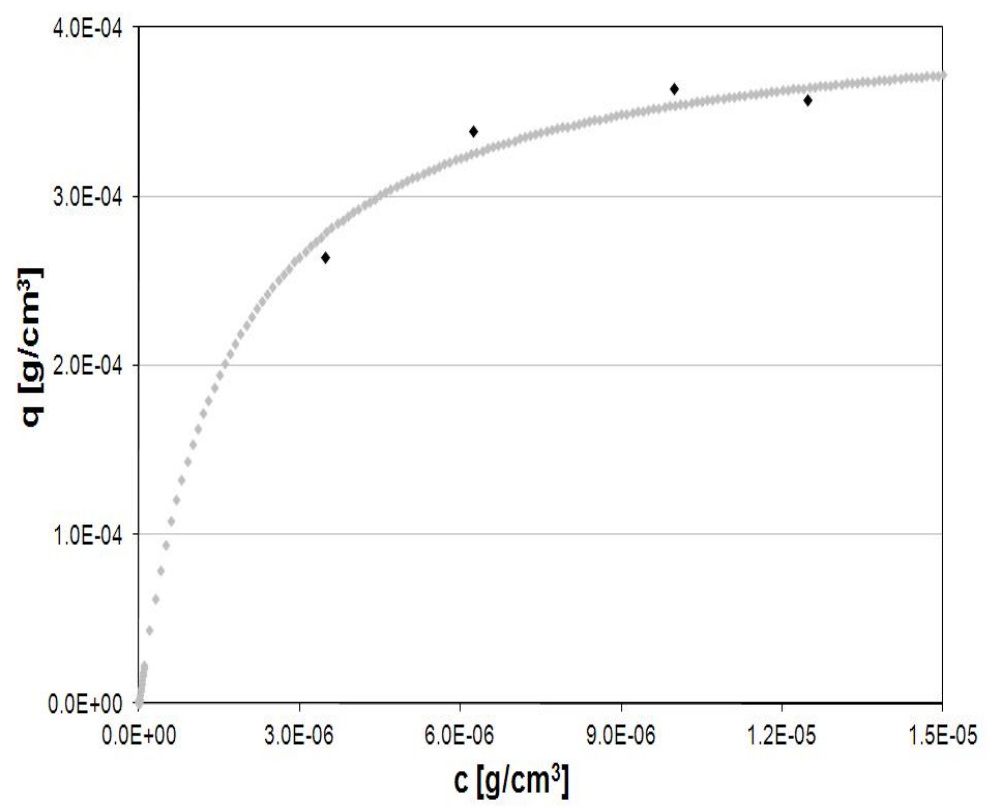

Fig. 2. Langmuir isotherm; point - experimental, line - modelled

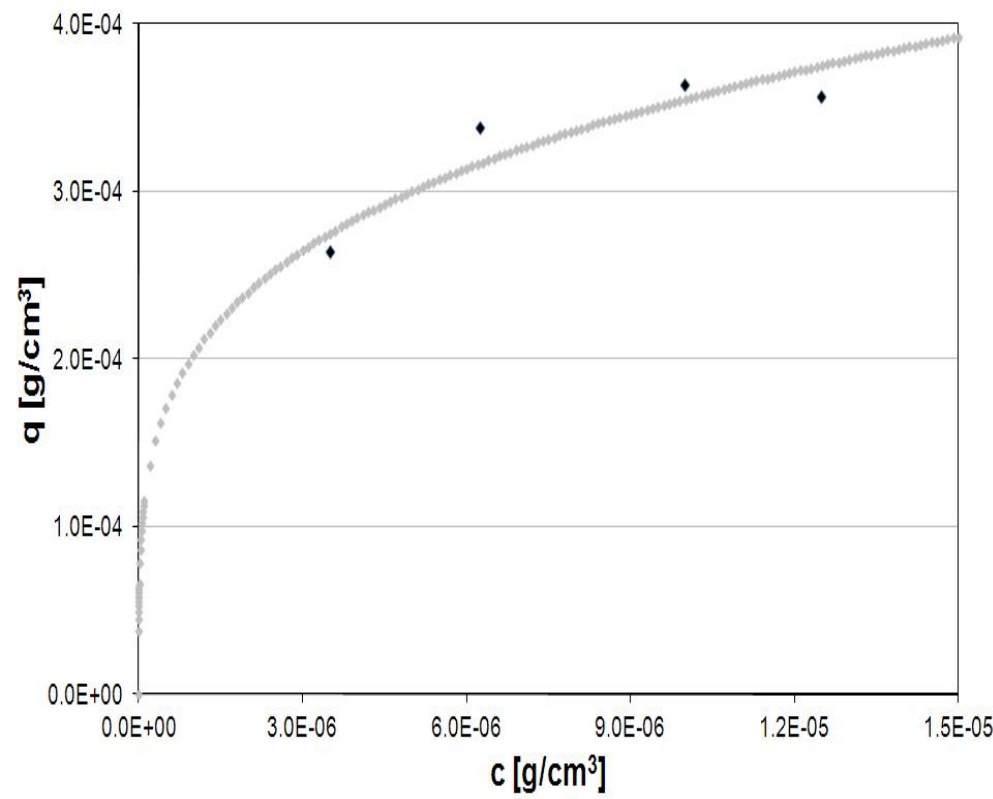

Fig. 3. Freundlich isotherm; point - experimental, line - modelled 


\subsection{Determination of bed porosity}

For LDF model it is necessary to determine bed porosity $\varepsilon$ which was calculated using Eq. (12) from the known volume, mass and density of adsorbent bed, described in (Amanullah, 2000; Holdich, 2002). The values of variables expressed in Eq. (12) are $V=163.43 \mathrm{~cm}^{3}, m=76 \mathrm{~g}, \rho_{p}=0.730{\mathrm{~g} . \mathrm{cm}^{-3}}^{-3}$ leading to bed porosity $\varepsilon=0.363$.

$$
\varepsilon=\frac{V-\frac{m}{\rho_{p}}}{V}
$$

The calculation of bed porosity $\varepsilon$ was compared with Eq.(13) according to work (Foumeny, 1990) where $d_{p, \text { spheric }}$ was in the range from $0.229 \mathrm{~cm}$ to $0.321 \mathrm{~cm}$. The average value of bed porosity calculated according to Eq. (13) was $\varepsilon=0.310$.

$$
\varepsilon=0.293+0.684 \cdot d_{r}^{-0.85} \frac{1}{\left(1.837 \cdot d_{r}-1\right)^{0.5}}
$$

The average value of bed porosity calculated according to Eq. (12) and (13) equal to 0.337 was used for further calculations.

\subsection{Determination of axial dispersion coefficient}

Axial dispersion coefficient $D_{L}$ can be calculated by Eq. (14) according to Edwards and Richardson (Amanullah, 2000), valid for $0.008<R e<50$ and $0.0037<d_{p}<0.6 \mathrm{~cm}$. Molecular diffusivity $D_{m}$ was calculated by Chapman-Enskog equation (Eq. 15) and for the mixture of $\mathrm{NO}$ and $\mathrm{N}_{2}$ was $0.1984 \mathrm{~cm}^{2} \cdot \mathrm{s}^{-1}$ (Table B-2, Bird 1960). The value of $D_{L}$ was equal to $0.1897 \mathrm{~cm}^{2} . \mathrm{s}^{-1}$.

$$
\begin{gathered}
D_{L}=0.73 \cdot D_{m}+\frac{0.5 \cdot v \cdot d_{p}}{1+\frac{9.7 \cdot D_{m}}{v \cdot d_{p}}} \\
D_{m}=0.0018583 \cdot \frac{\sqrt{T^{3} \cdot\left(\frac{1}{M_{A}}+\frac{1}{M_{B}}\right)}}{p \cdot \sigma_{A B}^{2} \cdot \Omega_{D_{A B}}}
\end{gathered}
$$

The extend of axial dispersion coefficient can be evaluated with Peclet number Pe. Axial dispersion coefficient may be neglected as Peclet number is above value of 100 (Amanullah, 1999). In our case, Peclet number was equal to 182 so that deviations from the ideal plug flow could be neglected. However, $D_{L}$ was also determined from the dispersion model expecting small deviation from plug flow, $\frac{D_{L}}{v \cdot L}<0.01$ (Levenspiel, 1979). The dependency of $\mathrm{F}$ curve on dimensionless time (obtained from the response of step input) showed a good agreement with $D_{L}$ calculated by Eq. (15). Therefore, $D_{L}$ term was left in Eq. (7) expecting low deviation from the plug flow.

\subsection{Determination of mass transfer coefficient $k$}

Mass transfer coefficients were determined by fitting the experimental data with the mathematical model (Eqs. 7, 8) with initial and boundary conditions (Eqs. 9-11) by the least squares technique in the computer program MATLAB. The constant parameters were bed porosity $\varepsilon$, axial dispersion coefficient 
$D_{L}$ and interstitial velocity $v$, while overall mass transfer coefficients $k$ were fitted for each experiment. The interstitial velocity $v$ was calculated according to Eq. (16), (Holding, 2002).

$$
v=\frac{v_{o}}{\varepsilon}
$$

Input data to the mathematical model are summarised in Table 2. Graphical outputs of experimental and modelled breakthrough curves with optimised overall mass transfer coefficients $k$ for each NO concentration are summarised in Fig. 4. Coefficients of determination $\mathrm{R}^{2}$ for each experiment were determined and are shown in Table 2.

Table 2. Input data to mathematical model and mass transfer coefficients obtained by fitting of experiments

\begin{tabular}{|c|c|c|c|c|c|c|c|}
\hline $\begin{array}{c}c_{0} \\
{\left[\mathrm{~g} \cdot \mathrm{cm}^{-3}\right]}\end{array}$ & $\begin{array}{c}q^{*} \\
{\left[\mathrm{~g} \mathrm{NO} . \mathrm{cm}^{-3} \text { a.u. }\right]}\end{array}$ & $\begin{array}{c}v_{0} \\
{\left[\mathrm{~cm} \cdot \mathrm{s}^{-1}\right]}\end{array}$ & $\begin{array}{c}v \\
{\left[\mathrm{~cm}^{-1}{ }^{-1}\right]}\end{array}$ & $\begin{array}{c}\varepsilon \\
{[-]}\end{array}$ & $\begin{array}{c}D_{\mathrm{L}} \\
{\left[\mathrm{cm}^{2} . \mathrm{s}^{-1}\right]}\end{array}$ & $\begin{array}{c}k \\
{\left[\mathrm{~s}^{-1}\right]}\end{array}$ & $R^{2}$ \\
\hline $1.25 .10^{-5}$ & $3.57 .10^{-4}$ & 0.64 & 1.90 & 0.337 & 0.19 & $2.40 .10^{-3}$ & 0.90 \\
\hline $9.98 .10^{-6}$ & $3.64 .10^{-4}$ & 0.64 & 1.90 & 0.337 & 0.19 & $1.72 .10^{-3}$ & 0.89 \\
\hline $6.24 .10^{-6}$ & $3.39 .10^{-4}$ & 0.64 & 1.90 & 0.337 & 0.19 & $9.96 .10^{-4}$ & 0.90 \\
\hline $3.49 .10^{-6}$ & $2.64 .10^{-4}$ & 0.64 & 1.90 & 0.337 & 0.19 & $6.64 .10^{-4}$ & 0.92 \\
\hline
\end{tabular}
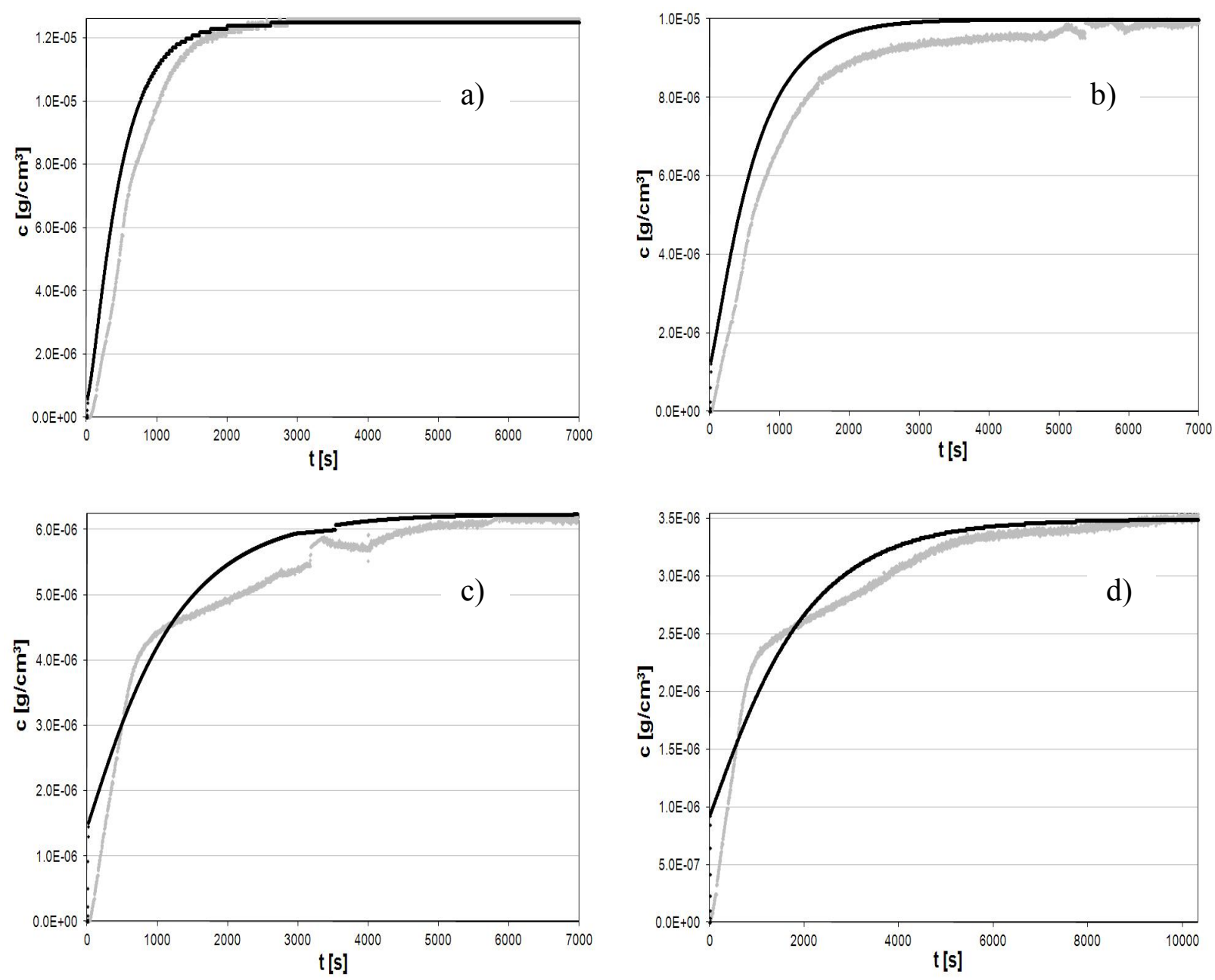

Fig. 4. Experimental and modelled breakthrough curves with optimised mass transfer coefficients $k$ for $c_{0}=1.25 .10^{-5} \mathrm{~g} . \mathrm{cm}^{-3}(\mathrm{a}), c_{0}=9.98 .10^{-6} \mathrm{~g} \cdot \mathrm{cm}^{-3}(\mathrm{~b}), c_{0}=6.24 .10^{-6} \mathrm{~g} \cdot \mathrm{cm}^{-3}(\mathrm{c})$ and $c_{0}=3.49 .10^{-6} \mathrm{~g} \cdot \mathrm{cm}^{-3}(\mathrm{~d})$, (black line - modelling; grey line - experimental). Note: The time periods when nonzero concentrations appeared at the beginning of breakthrough curves are not visible because of the scale of $x$ axes. 


\subsection{Estimation of surface diffusivity}

The evaluated overall mass transfer coefficients $k$ allowed to estimate contribution of surface diffusion to the diffusive transport of NO. During surface diffusion adsorbed species move across the interior adsorbent surface to other vacant adsorption sites. Surface diffusion is most likely to be significant in porous adsorbents with high surface area and narrow pores.

Overall mass transfer coefficient $k$ can be correlated to the external-film mass transfer coefficient $k_{f}$, effective macropore diffusivity $D_{p}$ and micropore diffusivity $D_{c}$ according to Eq. (17), (Amanullah, 2000; Dantas, 2011; Murillo, 2004; Tantet, 1995).

$$
\frac{1}{k}=\frac{r_{p}}{3 \cdot k_{f}} \cdot \frac{q^{*}}{c_{0}}+\frac{r_{p}^{2}}{15 \cdot \varepsilon_{p} \cdot D_{p}} \cdot \frac{q^{*}}{c_{0}}+\frac{r_{c}^{2}}{15 \cdot D_{c}}
$$

As described in (Amanullah, 2000), the third term in Eq.(17) can be neglected when particle diameter $d_{p}$ is higher than $1.5 \mathrm{~mm}$ hence adsorption is controlled by external and macropore diffusion. However, macropore diffusion (described by $D_{p}$ ) is due to a combination of molecular diffusion $D_{m}$, Knudsen diffusion $D_{k}$ and surface diffusion $D_{s}$ according to Eq. (18). This is in accordance with (Murillo, 2004) describing gas-phase diffusion in pores and surface diffusion on pore walls proceed in parallel.

$$
\frac{1}{D_{p}}=\frac{\tau_{p}}{D_{m}}+\frac{1}{\frac{D_{k}}{\tau_{p}}+\frac{1-\varepsilon_{p}}{\varepsilon_{p}} \cdot \frac{D_{s}}{\tau_{s}} \cdot \frac{q^{*}}{c_{0}}}
$$

While molecular diffusivity and Knudsen diffusivity can be evaluated from Eqs. (15) and (19), respectively, surface diffusivity cannot be easily measured directly.

$$
D_{k}=9700 \cdot r_{o} \cdot \sqrt{\frac{T}{M}}
$$

In this work, surface diffusivity was estimated from Eq. (18) using the value of $D_{p}$ calculated from Eq. (17) using the known value of $k$ determined by fitting experimental breakthrough curves. The value of average pore radius $r_{o}$ was used, as micropores were the most distributed pores in commercial activated carbon, which was in agreement with literature (Amanullah, 2000; Dantas, 2011). Mean pore radius was evaluated from $\mathrm{N}_{2}$ physical adsorption and $\mathrm{Hg}$ porozimetry and based on an assumption of cylindrical shape of pores $\left(r_{\mathrm{o}}=r_{\text {mean }}=2 \cdot\right.$ volume/surface area). The value of $D_{k}$ was $4.74 .10^{-3} \mathrm{~cm}^{2} \cdot \mathrm{s}^{-1}$ for $r_{o}=1.56 .10^{-7} \mathrm{~cm}$.

External-film mass transfer coefficient $k_{f}$ was calculated from Eq. (20).

$$
S h=\frac{2 \cdot r_{p} \cdot k_{f}}{D_{m}}=2+1.1 \cdot S c^{1 / 3} \cdot \mathrm{Re}^{0.6}, R e=0-1000
$$

The values of non-dimensional parameters needed in Eq. (20) were $R e=1.03, S c=0.76$ and $S h=3.02$.

It was also necessary to predict the values of the pore and surface tortuosities. In the absence of reliable information, the pore tortuosity and surface tortuosity were considered equal and a value of 4 was adopted according to (Murillo, 2004).

Results of calculation of surface diffusivities are summarised in Table 3. Surface diffusivity increases with an increase of the initial NO concentration (and equilibrium concentration of NO in the solid phase), since $D_{s}$ is strongly dependent on surface concentration which is proportional to the amount adsorbed (Thomas, 1998). The values of $D_{s}$ agree with values found in the literature, magnitude of $D_{s}$ has been reported to be within the range $10^{-3}$ to $10^{-6} \mathrm{~cm}^{2} \mathrm{~s}^{-1}$ (Murillo, 2004, Thomas, 1998). 
Table 3. Estimated values of surface diffusivity and variables needed for their calculation

\begin{tabular}{|c|c|c|c|c|}
\hline$c_{0}\left[\mathrm{~g} \cdot \mathrm{cm}^{-3}\right]$ & $q^{*} / c_{0}$ & $k_{f}\left[\mathrm{~cm} \cdot \mathrm{s}^{-1}\right]$ & $D_{p}\left[\mathrm{~cm}^{2} \cdot \mathrm{s}^{-1}\right]$ & $D_{s}\left[\mathrm{~cm}^{2} \cdot \mathrm{s}^{-1}\right]$ \\
\hline $1.25 .10^{-5}$ & 28.59 & 2.50 & $1.0 .10^{-4}$ & $2.0 .10^{-5}$ \\
\hline $9.98 .10^{-6}$ & 36.42 & 2.50 & $9.3 .10^{-5}$ & $1.4 .10^{-5}$ \\
\hline $6.24 .10^{-6}$ & 54.25 & 2.50 & $8.0 .10^{-5}$ & $8.2 .10^{-6}$ \\
\hline $3.49 .10^{-6}$ & 75.56 & 2.50 & $7.4 .10^{-5}$ & $5.5 .10^{-6}$ \\
\hline
\end{tabular}

\section{CONCLUSIONS}

The mathematical linear driving force (LDF) model using the method of least squares was used for solving the equations describing isothermal dynamic adsorption of NO in a fixed bed filled with activated carbon. The overall mass transfer coefficients obtained by fitting experimental breakthrough curves were increasing with higher initial NO concentrations confirming the presumption that equilibrium was reached faster. The overall mass transfer coefficients considering film resistance and pore resistance obtained by numerical modelling allowed to evaluate surface diffusivity of NO over the interior surface of activated carbon in the range $2.0 .10^{-5}-5.5 .10^{-6} \mathrm{~cm}^{2} . \mathrm{s}^{-1}$ for $1-0.28 \mathrm{~mol} \%$ initial NO concentrations.

This work was conducted under the financial support of Ministry of Industry and Trade of the Czech Republic; project No. 2A-2TP1/061, project SGS SP2011/91 and EU project No. CZ.1.05/2.1.00/03.0100 „Institute of Environmental Technologies “.

\section{SYMBOLS}

$b \quad$ Langmuir constant related to rate of adsorption, $\mathrm{cm}^{3} / \mathrm{g}$

$c \quad$ concentration of NO in time $t, \mathrm{~g} / \mathrm{cm}^{3}$

$c_{0} \quad$ initial concentration of NO in gas phase, $\mathrm{g} / \mathrm{cm}^{3}$

$\left.c\right|_{0} \quad$ concentration of $\mathrm{NO}$ at the inlet of adsorbent bed, $\mathrm{g} / \mathrm{cm}^{3}$

D diameter of adsorption column, cm

$D_{c} \quad$ micropore diffusivity, $\mathrm{cm}^{2} / \mathrm{s}$

$D_{p} \quad$ effective macropore diffusivity, $\mathrm{cm}^{2} / \mathrm{s}$

$D_{k} \quad$ Knudsen diffusivity, $\mathrm{cm}^{2} / \mathrm{s}$

$D_{L} \quad$ axial dispersion coefficient, $\mathrm{cm}^{2} / \mathrm{s}$

$D_{m} \quad$ molecular diffusivity, $\mathrm{cm}^{2} / \mathrm{s}$

$d_{p} \quad$ diameter of adsorbent particle, $\mathrm{cm}$

$\overline{d_{p}} \quad$ average diameter of adsorbent particles, $\mathrm{cm}$

$D_{s} \quad$ surface diffusivity, $\mathrm{cm}^{2} / \mathrm{s}$

$d_{p, s p h e r i c} \quad$ equivalent sphere particle diameter, $\mathrm{cm}$

$d_{r} \quad$ diameter ratio

$k \quad$ mass transfer coefficient, $1 / \mathrm{s}$

$k_{f} \quad$ external film mass transfer coefficient, $\mathrm{cm} / \mathrm{s}$

$K_{F} \quad$ adsorption coefficient for Freundlich isotherm, $\mathrm{g} / \mathrm{cm}^{3}\left(\mathrm{~cm}^{3} / \mathrm{g}\right)^{1 / n}$

$L \quad$ bed length, $\mathrm{cm}$

$m \quad$ mass of activated carbon in adsorbent bed, $g$

M molecular weight, $\mathrm{g} / \mathrm{mol}$ 


$\begin{array}{ll}n & \text { Freundlich constant } \\ p & \text { atmospheric pressure, } \mathrm{Pa} \\ P e & \text { Peclet number }\left(=L \cdot v / D_{L}\right) \\ q^{*} & \text { equilibrium concentration of NO in the solid phase, } \mathrm{g} / \mathrm{cm}^{3} \\ \bar{q} & \text { average concentration of NO in the solid phase, } \mathrm{g} / \mathrm{cm}^{3} \\ q_{s} & \text { Langmuir constant related to rate of adsorption, } \mathrm{g} / \mathrm{cm}^{3} \\ Q_{v} & \text { volumetric feed flow rate, } \mathrm{cm}^{3} / \mathrm{s} \\ r_{p} & \text { radius of adsorbent particle, } \mathrm{cm} \\ r_{o} & \text { average pore radius, } \mathrm{cm} \\ R e & \text { Reynolds number }\left(=\rho_{g} \cdot v_{0} \cdot d_{p} / \mu_{g}\right) \\ S c & \left.\text { Schmidt number }\left(=\mu_{g} \cdot D_{m} / \rho_{g}\right)\right) \\ S h & \text { Sherwood number }\left(=k_{f} d_{p} / D_{m}\right) \\ T & \text { temperature of the experiment, K } \\ t & \text { time, s } \\ t_{t} & \text { time equivalent to total or stoichiometric capacity, } \mathrm{s} \\ V & \text { bulk volume of bed, } \mathrm{cm}{ }^{3} \\ v & \text { interstitial gas velocity }, \mathrm{cm} / \mathrm{s} \\ v_{0} & \text { superficial gas velocity, } \mathrm{cm} / \mathrm{s} \\ y & \text { mole fraction of NO in feed } \\ z & \text { distance from the inlet of the adsorbent bed, cm }\end{array}$

Greek symbols

$\begin{array}{ll}\varepsilon & \text { bed porosity } \\ \varepsilon_{p} & \text { particle porosity } \\ \mu_{\mathrm{g}} & \text { gas dynamic viscosity, Pa.s } \\ \rho_{\mathrm{p}} & \text { density of adsorbent particle, } \mathrm{g} / \mathrm{cm}^{3} \\ \rho_{\mathrm{g}} & \text { gas density, } \mathrm{kg} / \mathrm{m}^{3} \\ \rho_{\mathrm{NO}} & \text { NO density, } \mathrm{g} / \mathrm{cm}^{3} \\ \tau_{p} & \text { pore tortuosity } \\ \tau_{s} & \text { surface tortuosity } \\ \sigma_{\mathrm{AB}} & \text { constant in the Lennard-Jones potential function } \\ \Omega_{\mathrm{AB}} & \text { collision integral }\end{array}$

$\begin{array}{ll}\text { Subscripts } & \\ 0 & \text { initial } \\ f & \text { film } \\ g & \text { gas } \\ p & \text { particle } \\ s & \text { saturation } \\ v & \text { volumetric }\end{array}$

\section{REFERENCES}

Amanullah Md., Farooq S., Viswanathan S., 1999. Modeling and simulation of biofilter. Ind. Eng. Chem. Res., 38, 2765 - 2774. DOI: 10.1021/ie9807708.

Amanullah Md., Viswanathan S., Farooq S., 2000. Equilibrium Kinetics, and Column Dynamics of Methyl Ethyl Ketone Biodegradation. Ind. Eng. Chem. Res., 39, 3387-3396. DOI: 10.1021/ie000265m.

Babu B.V., Gupta S., 2005. Modeling and simulation of fixed bed adsorption column: effect of velocity variation. Retrieved 2005, from http://discovery.bits-pilani.ac.in/ bvbabu/JET_Ads_imanager_2005.pdf.

Bird R.B., Stewart W.E., Lightfoot E.N., 1960. Transport Phenomena. Wiley: New York, 532 - 533. 
Dantas T.L.P., Luna F.M.T., Silva Jr.I.J., Azevedo D.C.S., Grande C.A., Rodrigues A.E., Moreira R.F.P.M., 2011. Carbon dioxide-nitrogen separation through adsorption on activated caron in a fixed bed. Chem. Eng. J., 169, 11-19. DOI: 10.1016/j.cej.2010.08.026.

Foumeny E.A., Benyahia F., 1991. Predicive characterization of mean voidage in packed beds. Heat Recovery Syst. CHP, 11 (2/3), 127-130.

Gómez-García M.A., Pitchon V., Kiennemann A., 2005. Pollution by nitrogen oxides: an approach to NOx abatement by using sorbing catalytic materials. Environ. Int., 31, 445-467. DOI: 10.1016/j.envint.2004.09.006.

Gupta A., Gaur V., Verma N., 2002. Breakthrough analysis for adsorption of sutur-dioxide over zeolites. Chem. Eng. Process., 43, 9-22. DOI: 10.1016/S0255-2701(02)00213-1.

Herčík M., 2004. Environmental protection and legislation. Vysoká škola podnikání, a.s., Ostrava (in Czech).

Holdich R.G., 2002. Fundamentals of Particle Technology. Loughborough, U.K.

Levenspiel O., 1979. The Chemical Reactor Omnibook. Oregon State University, 64.2 - 64.11.

Murillo R., García T., Aylón E., Callén M.S., Navarro M.V., López J.M., Mastral A.M., 2004. Adsorption of phenanthrene on activated carbons: Breakthrough curve modelling. Carbon, 42, 2009-2017. DOI: 10.1016/j.carbon.2004.04.001

Mutlu M., Gökmen V., 1998. Determination of effective mass transfer coefficient $\left(K_{c}\right)$ of Patulin adsorption on activated carbon packed bed columns with recycling. J. Food Eng., 35, 259-266. DOI: 10.1016/S02608774(98)00914-5.

Ruthven D.M., 1984. Principles of adsorption and adsorption processes. John Wiley \& Sons, New York, 206 244.

Sircar S., Hufton J.R., 2000. Why does the linear driving force model for adsorption kinetics work? Adsorption, 6, 137 - 147. DOI: 10.1023/A:1008965317983.

Šrámek M., Ditl P., Neumanová E., 2005. Modelling and simulation of adsorption in fixed bed. Conference ChemPor 2005. Coimbra, Portugal.

Sumathi S., Bhatia S., Lee K.T., Mohamed A.R., 2010. Adsorption isotherm models and properties of $\mathrm{SO}_{2}$ and NO removal by palm shell activated carbon supported with cerium (Ce/PSAC). Chem. Eng. J., 162, 194-200. DOI: $10.1016 /$ j.cej.2010.05.028.

Tang D., Jess A., Ren X., Bluemich B., Stapf S., 2004. Axial dispersion and wall effects in narrow fixed bed reactors: A comparative study based on RTD and NMR measurements. Chem. Eng. Technol., 27 (8), 866-873. DOI: $10.1002 /$ ceat.200402076.

Tantet J., Eric M., Desai R., 1995. Breakthrough study of adsorption and separation of sulfur dioxide from wet gas using hydrophobic zeolites. Gas. Sep. Purif., 9 (3), 213-220. DOI: 10.1016/0950-4214(95)98229-E.

Thomas W. J., Crittenden B., 1998. Adsorption technology and design, Butterworth-Heinemann.

Zhang W.J., Rabiei S., Bagreev A., Zhuang M.S., Rasouli F., 2008. Study of NO adsorption on activated carbons. Appl. Catal. B, 83, 63-71. DOI: 10.1016/j.apcatb.2008.02.003.

Zhu J.L., Wang Y.H., Zhang J.C., Ma R.Y., 2005. Experimental investigation of adsorption of $\mathrm{NO}$ and $\mathrm{SO}_{2}$ on modified activated carbon sorbent from flue gases. Energy Convers. Manage., 46, 2173-2184. DOI: 10.1016/j.enconman.2004.10.011.

Received 22 July 2011

Received in revised form 12 December 2011 Accepted 16 December 2011 